\title{
Political Anti-Intentionalism
}

\author{
Matthias Brinkmann ${ }^{1}$
}

Published online: 5 January 2017

(C) The Author(s) 2017. This article is published with open access at Springerlink.com

\begin{abstract}
There has been little debate in political philosophy about whether the intentions of governments matter to the legitimacy of their policies. This paper fills this gap. First, I provide a rigorous statement of political anti-intentionalism, the view that intentions do not matter to political legitimacy. I do so by building on analogous debates in moral philosophy. Second, I sketch some strategies to defend political anti-intentionalism, which I argue are promising and available to a wide range of theories of legitimacy. Third, I show that the distinction has implications for debates surrounding neutrality and political liberalism.
\end{abstract}

Keywords Legitimacy · Intentions · Neutrality · Political liberalism

\section{Introduction}

Political decisions must be legitimate. But which features explain their legitimacy? We can think of a political decision as having the following structure:

an agent or group of agents $\mathrm{A}$, after having followed procedure $\mathrm{P}$, make a decision with content $\mathrm{C}$, which has (foreseeable) outcomes $\mathrm{O}$, while having intention I. ${ }^{1}$

There have been mountains of literature on the role of the first four variables. Most theorists agree that it matters in some way who decides, how decisions are made, what is decided, and what the outcomes of a decision are. In this paper, I explore the

\footnotetext{
1 Adapted from Patten (2011, p. 254).

Matthias Brinkmann

matthias.brinkmann@philosophy.ox.ac.uk

1 Magdalen College, Oxford OX14AU, UK
} 
fifth question, which has been mostly ignored: ${ }^{2}$ do the intentions for which a political decision was made matter, by themselves, to its legitimacy? We can call the position that they do intentionalism, and the claim that they do not antiintentionalism. Existing theories of legitimacy usually do not rule in or out either of these positions. My aim is to fill this gap. I will provide a precise statement of intentionalism and anti-intentionalism. In addition, I will suggest some tentative arguments in favour of anti-intentionalism.

One important upshot of this paper is that it clarifies two other debates. Many political liberals and defenders of neutrality of justification appear to advocate intentionalism insofar as they prohibit that governments act for certain reasons. However, I will argue that advocates of these theories are often ambiguous about the precise content of their theories in this respect. This paper clarifies what consistently intentionalist and anti-intentionalist readings of such theories look like.

Fortunately, we need not develop the subject matter from scratch. Many philosophers have discussed the role of intentions for moral permissibility. My strategy is to exploit the work of these philosophers to develop its political cousin. I first describe moral anti-intentionalism, and sketch the main philosophical motivations for this view. I then transpose the debate to legitimacy and offer some arguments in favour of political anti-intentionalism. Lastly, I show how these distinctions help us to understand the position of justificatory neutralists and political liberals.

Before we start, let me describe my general approach to the problem of legitimacy. I understand legitimacy normatively, as the right to rule. For the purposes of this paper, we can set aside many particular issues regarding this concept - in particular, whether we should see legitimacy as a liberty-right, claimright or power-right, and whether legitimacy entails duties to obey. I will also focus on the legitimacy of particular policies and laws, while other authors emphasise the legitimacy of political institutions. I briefly discuss what difference this focus would make later.

There is a wealth of methods to approach the problem of legitimacy. On the one hand, political realists claim that legitimacy is a genuinely political value which is wholly or mostly independent from ethics. Instead, realists argue, thinking about legitimacy should start from a close study of the actual practice of politics. ${ }^{3}$ On the other end of the scale, we get what political realists derisively call political moralism. Moralists at their most extreme see a theory of legitimacy purely as a derivative of a theory of morality-e.g. Kantian deontology. For such theorists, the social and political features of actual societies play little to no direct role in deriving the fundamental norm of legitimacy.

My approach might look like a moralist one, given that I heavily build on work done by moral philosophers. But I merely compare the two fields; I do not claim that one derives from, or is a mere extension of, the other. In fact, one of the main upshots of this paper is that there is an asymmetry between the two: the argument

\footnotetext{
2 The main exceptions are Enoch (2007), Wall (2001).

3 There is little agreement on the positive methodology of political realism; this description is intended to cover a wide variety of proposals. For an overview, see Rossi and Sleat (2014).
} 
for anti-intentionalism is stronger, and situated differently, when we look at the political case. So you might combine an intentionalist approach to moral permissibility with an anti-intentionalist theory of political legitimacy. Furthermore, one of the arguments I consider (from the functional role of the value of legitimacy) is amenable to many realists. Still, my approach tends towards the moralist end of thinking about legitimacy, in particular with regard to the level of abstraction I favour in normative theorising. I do not have the space to defend this approach here, though I do not wish to claim that it is the only valid way to look at legitimacy.

\section{Moral Anti-Intentionalism}

As suggested, I will first take a detour through ethics before I turn to political philosophy. Let us start with an example I will use throughout the paper to illustrate moral anti-intentionalism:

The GAngster. In all his actions, the Gangster shows no moral regard for other people, and intends to use all of them merely as means to his self-interested ends. The Gangster enters a coffee shop to buy a coffee from Smith. The Gangster is indifferent to Smith's life, and would torture, maim or kill Smith if that provided him with even slight enjoyment. However, in this particular instance the Gangster acts as most people would: he queues, orders, waits, pays, and leaves. ${ }^{4}$

The anti-intentionalist claims that the Gangster acted permissibly; or more precisely, if he acted impermissibly, this is not because of his intentions. We can reconstruct the main claim of the anti-intentionalist as follows:

Moral Anti-Intentionalism. Whether an action is permissible does not fundamentally depend on which intentions the agent had in performing that action. $^{5}$

Let me explain the crucial ingredients. First, anti-intentionalism is a claim about the independence of permissibility from intentions. We can roughly think of an intention as the plan an agent had when she performed an action, or as the part of an overall plan she had. This is meant to be a generic description of intentions which keeps the notion on an intuitive level. In this way, I hope to bypass many of the more controversial debates surrounding the precise nature of intentions. The Gangster plans to use everyone merely as a means, and his treatment of Smith is a part of that plan. This is enough for us to say that he intends to use Smith merely as a means.

Some moral philosophers focus on the motive-independence of permissibility instead of the intention-independence (e.g. Timmons 2002; Sverdlik 2011). Mark Timmons claims that motives are psychological states that reveal 'some goal or end that the agent finds attractive or desirable for its own sake and in terms of which the

\footnotetext{
4 Modified from Scanlon (2008, pp. 99-100), Parfit (2011, pp. 216-217).

5 For other formulations, see Timmons (2002, p. 262), Sverdlik (2011, p. 3), Liao (2012, p. 704).
} 
agent's interest in [...] some course of action can be explained' (Timmons 2002, p. 264). On that account, the specific plans you choose (your intentions) are distinct from the ends for which you choose those plans (your motives). This is a plausible distinction to make, but we need to take no stance on this issue for the purposes of this paper. Nothing in it hangs on how one draws out the relation between intentions and motives, and other mental states such as desires. With some tweaks, it is likely that a similar argument could be provided for the motive- or desire-independence of legitimacy.

Another observation is that intentions exist on more fine-grained and coarsegrained levels, and that one and the same action can be done with different intentions. ${ }^{6}$ As a sub-plan of his plan to use everyone merely as a means, the Gangster has some intentions which are morally unproblematic ('I reach out my hand so that Smith can give me my change'). This is not an obstacle for the intentionalist: she merely claims that on some intentional description of an action, the agent has inadmissible intentions, and thus acts wrongly. The issue gets more difficult if an agent has muddled or conflicting intentions, but I will set such cases aside.

Second, moral anti-intentionalism is a claim about the permissibility of actions. An important move of anti-intentionalists is to accuse the intentionalists of confusing permissibility with other 'moral dimensions'. 7 Two ideas are common. Judith Jarvis Thomson emphasises that we should distinguish the evaluation of agents from the evaluation of actions (Thomson 1999, p. 517). The Gangster can be criticised as a person in various ways. We might say that the Gangster is a vicious and repugnant brute. But the anti-intentionalist insists that this leaves the permissibility of his coffee-buying untouched.

A second idea is that an action itself can be assessed along various dimensions. Imagine that Mahatma Gandhi is grumpy in the morning, and finds himself wanting to use Smith merely as a means. Gandhi exhibits a moral lack in this situation, but it is implausible to locate it in his character. Here we can turn to a distinction from Scanlon, who argues that we should separate the permissibility of an action from its 'meaning', in particular from its blameworthiness (Scanlon 2008, pp. 52-55). We can say that Gandhi acted permissibly, but that his coffee-buying was morally criticisable in other ways-for example, as inconsiderate. This provides us with another anti-intentionalist argument strategy. For any set of counter-examples, the anti-intentionalist can argue that on closer inspection these examples are not really about permissibility, but some other moral quality. ${ }^{8}$ I think that this strategy is decisive in the Gangster case.

A third clarification is that the defender of anti-intentionalism claims that intentions fundamentally do not matter, but she can accept that they matter derivatively. Indeed, denying so would be absurd (for some examples, see Kolodny 2011, p. 101; Liao 2012, p. 709). First and foremost, intentions can change the

\footnotetext{
${ }^{6}$ I thank an anonymous reviewer for raising this point.

7 The phrase is from Scanlon (2008, pp. 21-23). See also Enoch (2005, p. 46), Hanser (2005, p. 454), Walen (2006, p. 62), (van Zyl 2008, p. 96).

${ }^{8}$ For an example of this strategy in action, see van Zyl (2010, pp. 410-413).
} 
consequences of an action. ${ }^{9}$ Assume that the Gangster's intentions show themselves in subtle clues which Smith can perceive. Understanding these clues induces fear and terror in Smith, which makes his life much worse. This is enough to make the Gangster having those intentions impermissible. But this is not a sufficient example to show that intentions do not matter fundamentally: intentions here merely matter insofar as they change the consequences.

Another important way in which intentions matter derivatively is by changing the nature of an action. Compare the Gangster with Mary, a virtuous and law-abiding citizen, who also buys coffee from Smith. There are various counterfactuals which are true of the Gangster which are not true of Mary. For example, if Smith would be slow in serving the Gangster, he would fall into a rage and seriously harm Smith. The same is not true of Mary. ${ }^{10}$ When we compare the Gangster's coffee-buying and Mary's coffee-buying, we compare someone letting Smith barely get away with his life to someone doing a routine transaction with Smith. The first is wrong, the second is not. But given this, it is not the case that the intention by itself changes the wrongness of the action. Rather, the intention changes the nature of the action by giving it an additional feature (the risk of being harmed) such that the action is wrong on account of this non-intentional feature.

To see this, assume that Gregor knows that a violent twitch overcomes him whenever he enters coffee houses. This twitch would make him harm Smith with a certain probability in ways similar to the Gangster. It would be wrong for Gregor to order a coffee from Smith, because it would be wrong to impose this risk of being harmed on Smith. But we need not know anything about Gregor's intentions to make this judgement. Imposing a risk on innocents to be harmed when buying coffee is wrong in an intention-independent way.

\section{Strategies for Moral Anti-Intentionalism}

The debate between moral intentionalism and anti-intentionalism will be decided on two fronts. First, we need to see whether the two positions can account for various intuitions about particular cases. Second, we need to consider whether there is a convincing, general rationale in favour of either position. I will discuss these in turn, again with a special focus on anti-intentionalism.

On the first point, there is a large set of common examples which appear to support intentionalist moral principles. To cite a classic example, many philosophers have claimed that there is a moral asymmetry between the impermissible harm done by terrorists and the permissible collateral damage inflicted by a just combatant. Intentionalist principles such as the doctrine of double effect provide a simple and elegant explanation of such judgements. ${ }^{11}$

\footnotetext{
9 Scanlon (2008, p. 13) calls this the 'predictive significance of intent'.

10 Another example to a similar effect is given by Herman (2011, p. 88).

11 E.g. McMahan (2009), Kolodny (2011). Many anti-intentionalists agree that their position is the less intuitive one-e.g., Enoch (2005), Scanlon (2008).
} 
Anti-intentionalists have four strategies available to them in response. First, they can lead a countercharge, claiming that intentionalist principles also lead to counterintuitive results, and that anti-intentionalism is not relevantly worse in this respect (e.g. Thomson 1985). A second response is to argue that purported intuitions about such cases on closer inspection do not contradict anti-intentionalism after all. The strategy of distinguishing moral dimensions is one way to pursue this response. Third, one might look to account for such intuitions through non-intentionalist principles. This is also a strategy I have already sketched: wherever it seems that intentions matter, we look for a more fundamental, non-intentionalist principle that explains the relevant difference (e.g. Kamm 2007, chs. 3-4; Scanlon 2008, ch. 2). Lastly, the anti-intentionalist can accept that her position violates some intuitive judgements about permissibility, but that we should favour the position at any rate given its other advantages.

Most anti-intentionalists see the strength of their view in such general moral considerations. A first is the advantage of simplicity: anti-intentionalism relies on fewer metaphysical ingredients in explaining permissibility. ${ }^{12}$ Another motivation for anti-intentionalism stems from consequentialism. On standard consequentialism, the permissibility of an action merely rests on its consequences-intentions matter only derivatively. ${ }^{13}$ But one need not be a consequentialist to find anti-intentionalism appealing. The basic idea is that permissibility is outward-looking. The reasons we have for or against some action are provided by the features of that action which speak for or against it. Once we have learned all the relevant features of an action-including its consequences—we can determine its permissibility on that basis alone.

Scanlon claims that permissibility finds its primary role in the practical, firstperson deliberation of agents: people asking themselves 'what may I do?' He argues that intentions are irrelevant from that perspective. In deciding what I may do, I weigh the merits and demerits of the options in front of me; it would be strange, he argues, if I additionally counted my own intentions I would have if I acted in certain ways. Scanlon accepts that intentions can matter from a third-person perspective when we evaluate how others act. There it becomes important whether people were sensitive to the right reasons when they decided what to do. But permissibility is not located on this level, Scanlon claims: it belongs primarily to the deliberative perspective of agents (Scanlon 2008, pp. 21-24).

This is only a brief sketch of some lines of argument for moral antiintentionalism. It is not my aim to defend moral anti-intentionalism in this paper. As I noted in the Introduction, I merely use the analogy as a device to transpose ideas. So we have to check independently whether anti-intentionalist arguments make sense when we apply them to legitimacy. Let us turn to this task now.

\footnotetext{
12 As an anonymous reviewer has pointed out, anti-intentionalism is not simpler in every way: a nonintentionalist equivalent of the doctrine of double effect, for example, is likely to be more complex in terms of content.

13 You might include acting on good intentions amongst what makes consequences good, but such a move looks little in keeping with the general spirit of consequentialism. However, see Sverdlik (1996, pp. 347-348).
} 


\section{Political Anti-Intentionalism}

We can give a straight forward definition of the view at the core of this paper by building on its moral analogue:

Political Anti-Intentionalism. Whether a political decision is legitimate does not fundamentally depend on which intentions the rulers had in making that decision.

The political intentionalist denies this. She claims that at least some forms of governmental intention, at least sometimes, will by themselves make an otherwise legitimate decision illegitimate. ${ }^{14}$

To make the issue more vivid, let us focus on an example. We need a situation in which we can separate the effect that intentions have on the legitimacy of a decision from the effects of its other features. We often encounter policies where their legitimacy, or lack thereof, is severely overdetermined. This makes it hard to get a grip on whether intentions independently matter. Here is a case to avoid these pitfalls, the case of the:

Benign Fanatics. Consider a democracy where a group of religious fanatics has been voted into power according to the procedures determined in that country's liberal constitution. There already is a minimally just system of social redistribution in place in this society. The fanatics design a new system of social redistribution which would greatly improve upon the existing system, according to our best liberal theory of justice. ${ }^{15}$ In making that decision, the fanatics follow established legal procedures. They also give everyone a fair hearing in the process, and deliberate open-mindedly with citizens. The fanatics also try to provide citizens with reasons in favour of the reform which everyone can reasonably accept.

However, the benign fanatics choose this system for theological reasons, and their intention in doing all this is to bring about the Kingdom of God. They believe that proper judgement belongs only to God, and not to them. Therefore, they believe, they ought to treat everyone equally and fairly till the Day of Judgement, and respect them as persons. (The fanatics reject this liberal vocabulary and phrase these ideas in religious language.) Secularism and atheism, they think, rest on deep and fundamental mistakes, and atheists are in principle doomed.

On the question of who decides, how the decision is made, what is decided, and what outcomes it will have, liberal theories of legitimacy will find it hard to find a fault with the fanatics. So if the reform falls short of being fully legitimate, this must

\footnotetext{
${ }^{14}$ We might ask whether intentions only negatively affect legitimacy, or whether they can also positively contribute towards making a decision legitimate. My focus in this paper is on the former, but nothing in principle stops the intentionalist from accepting the latter.

15 Matthew Liao has argued that anti-intentionalist thought experiments often confound our intuitions by appealing to a 'must act' factor-that not acting would lead to disaster (Liao 2012, pp. 712-717). To not fall into this trap, I have assumed that if the fanatics did not act, that would not lead to disaster.
} 
be due to the theological intentions of the fanatics. The reasons the benign fanatics act on are examples of reasons that liberals classically find problematic: they are reasons that 'not everyone can reasonably accept', and which are not part of public reason. These are prime candidates for the kind of intentions which would negatively affect legitimacy.

Against such theories, I sympathise with the claim that the benign fanatics' situation is analogous to the Gangster's. We should say that their reform project is fully legitimate. If it lacks legitimacy, then it lacks it because of how it was decided, or because of its content, or some other such feature; but not because it has been decided with inadmissible theological intentions. Note that I agree that the fanatics' intentions are inadmissible: they should not have had them, just as the Gangster should not have intended to use Smith merely as a means.

Like the case of the Gangster, this is merely a motivating example, and more needs to be done to extrapolate from this case a general argument for antiintentionalism. Like moral anti-intentionalism, the case for political anti-intentionalism will be decided on a concrete front-its ability to account for a variety of judgements regarding particular policies and cases_-and on an abstract front, that is, the general theoretical considerations speaking in its favour.

Before I turn to that discussion, I wish to highlight a first difference between the moral and the political arguments in this respect. This difference concerns the comparative weight which we should assign to these two sets of considerations. When we look at the issue of political intentionalism versus anti-intentionalism, I believe that much greater weight should be put on the abstract support these positions enjoy. The reason for this is that while we have strong and reliable intuitions about moral permissibility, intuitions regarding legitimacy are much weaker and less reliable. First, there is a wide set of test cases in moral philosophy-from run away trolleys to doctors cutting up patients-which normative theories have to get right. The intuitive method in ethics is contested, of course, and some philosophers reject it altogether. But at least some intuitive cases seem wide-spread and generally accepted. This makes it a pressing task for a moral theory to either account for these intuitions, or to have a convincing error theory explaining these intuitions away. If we fail in this task, then abstract considerations are unlikely to sway us.

Legitimacy, I believe, is different in this respect. We do not have the same established set of examples as we do in moral philosophy. I do not mean to say that we have no intuitions about legitimacy. It is likely that you had some form of reaction to the example of the benign fanatics. But I am inclined to think that, whatever your reaction, it would not be a knockdown argument against a theory of legitimacy if it could not account for it.

Second, it strikes me that judgements we make about legitimacy tend to rely much more on background theories than judgements about permissibility. The classic trolley-style cases in moral philosophy usually elicit reactions which are independent from our exposure to particular moral theories; so there is some point in giving them independent weight. Intuitions about legitimacy, on the other hand, are much more theory-dependent. Most of us will make judgements about legitimacy on the basis of some background theory-if only a 'folk theory' — which determines 
how legitimacy is linked to legality, democratic procedures, good outcomes, or some such. But then it is harder to see why we should give such intuitions independent weight.

This is partially due to legitimacy not being a thin concept such as permissibility. Before you can make any judgements about legitimacy, you already need not have a rough conceptual map of how it fits in with other values and political concepts. The same is not true of permissibility. So our intuitions regarding legitimacy are more sensitive to substantive background commitments. This is partially reflected in how most philosophers tend to theorise about legitimacy. The type of moral theorising which relentlessly appeals to intuitions about thought experiments is comparatively rare in theories of political legitimacy, and I think this reflects good philosophical practice.

This is a gradual distinction between theorising about permissibility and legitimacy - it is not to say that appealing to intuitions never has a place in thinking about legitimacy. Still, my focus in the following will be on general, abstract reasons to favour political anti-intentionalism, as I suspect this will be the main battleground in the debate.

\section{Strategies for Political Anti-Intentionalism}

Let us turn to arguments in favour of political anti-intentionalism. The first three points I wish to make are modelled closely on related points I discussed in the moral case: we need to say something about governmental intentions, about moral dimensions, and the idea of fundamentality. Then I sketch a general line of argument in favour of political anti-intentionalism.

\section{Sceptical Arguments}

We can start with the claim that governments do not have intentions, because they are not the kind of entity which could have intentions. Governments are not individuals, but complex groups of people acting together. But groups, so the objection goes, do not have intentions. Thus, political anti-intentionalism is trivially true: what does not exist cannot matter.

This strong form of scepticism strikes me as implausible. We often ascribe intentions to governments. We say, for example, that the United States invaded Iraq in 2004 because it intended to depose Saddam Hussein, and it acted on the belief that Iraq had weapons of mass destruction (e.g. Cryer and Simester 2005). Open any newspaper or history book, and you find claims about what 'Britain', 'the Ministry of Health', or other political institutions want, intend and desire. The sceptic might reply that such ascriptions are merely useful fictions: strictly speaking, all such claims are false. ${ }^{16}$ This is an unconvincing position which is opposed by a growing

${ }^{16}$ For a discussion and rejection of this view, see Copp (2006). 
consensus in the philosophical literature that groups can be agents with beliefs, desires and intentions (e.g. List and Pettit 2011).

I return to a more moderate form of scepticism about governmental intentions below. But I will assume throughout that there is no principled problem with ascribing intentions to governments and political bodies. So I am concerned with a conditional question: assuming that some convincing metaphysical account of collective intentions can be given, do they matter to legitimacy?

\section{Moral Dimensions}

We can first return to the moral dimensions strategy. Political anti-intentionalism is a claim about the legitimacy of decisions. This means, first, that it is not a claim about rulers-e.g. it is not a claim about the benign fanatics themselves. The fanatics are morally lacking in various ways. In particular, they are unreasonable in the Rawlsian sense: they are unwilling to propose and act on the basis of terms of cooperation acceptable to everyone. We should criticise the fanatics for being unreasonable, and should prefer rulers who are reasonable. However, political antiintentionalism makes no claim about the benign fanatics. It focusses on the legitimacy of the decisions themselves.

We can now turn to an issue I mentioned in the Introduction. Many theorists focus on the legitimacy of rulers or constitutions, and make individual decisions secondary. On this picture, an individual policy is legitimate just in case it has been made by a legitimate ruler (unless, perhaps, it is intolerably unjust), or is the outcome of a legitimate procedure. I do not think this is a plausible view. That a decision was made by legitimate political institutions might establish a presumption in favour of its legitimacy, but there are still independent questions to be asked on the level of decisions themselves.

At any rate, if you accept the proceduralist picture, this actually enhances the case for anti-intentionalism. First, the legitimacy of individual decisions is now nonintentionalist, as their legitimacy derives solely from their origin. Second, it is hard to see how intentions would matter in assigning legitimacy to political institutions. It is one thing to claim that the benign fanatics' bad intentions undermine the legitimacy of their welfare reform; it is a much stronger claim that their intentions undermine that they are legitimate rulers in the first place. Furthermore, the proceduralist picture will strongly incline us to think of them as legitimate rulers, as they have been properly elected. In short, strong proceduralism about legitimacy enhances the case for anti-intentionalism, as it crowds out how intentions could matter.

A second way to pursue the moral dimensions strategy is to distinguish the legitimacy of a political decision from its other features, in particular its merits. ${ }^{17}$ Amongst the merits of a decision are its justice, goodness, fairness, reasonableness and efficiency. It is plausible to think that the fanatics' intentions affect these

\footnotetext{
17 This distinction is famously made (under the labels 'legitimacy' and 'justification') in Simmons (1999).
} 
various dimensions. We might think that the fanatics' intentions make their welfare reform (pro tanto) unjust, unfair and unreasonable, without making them illegitimate.

Let me focus on the justice-legitimacy difference in particular. I do not have the space to consider whether intentions matter to justice, but there are some prima facie considerations in favour of this idea. It seems to matter for justice not merely whether people's rights are respected de facto, but also whether rulers regard their citizens in the right way. For these reasons, we might think that the benign fanatics' treatment of their citizens is not perfectly just. However, legitimacy enjoys a significant degree of independence from justice. A decision can be unjust while still being legitimate. ${ }^{18}$ It is true that grave injustice could undermine the legitimacy of a decision. But acting with the fanatics' intentions is not unjust to the degree necessary to undermine legitimacy. This provides the anti-intentionalist with a simple and elegant line of argument.

\section{The Concept of Legitimacy}

It is now time to say a few words about legitimacy. There are two main ways to understand the concept-first, as a permission to rule, and second as a right to rule. I will not decide the issue in this paper. Let me instead highlight how specific versions of the moral dimensions strategy can be pursued with regard to both.

Most theorists understand legitimacy as the right to rule. One standard way to make this understanding more precise is to see legitimacy as the Hohfeldian claimright to be obeyed. Insofar as legitimacy is understood as a right to make a decision, there is strong pressure toward anti-intentionalism. The task of rights is to carve out separate spheres of freedom for different agents. A property right over your pen gives you wide freedoms over how to use it, sell it, improve it, break it, give it away and so on. This right finds its limits in the freedoms of other people. But otherwise, if someone has a right, this isolates their actions from certain kinds of moral criticism. You might use your pen unwisely and wastefully, and this will reflect badly on you. None of this, however, diminishes your having a right to your pen. It is permissible for you to use your pen badly, precisely because you have a right to it. ${ }^{19}$

There is an important substantive point here, which all plausible theories of rights should accept. We use rights language as a second-order device that blocks out certain kinds of moral criticism-criticism phrased in terms of virtue, goodness, humanity, charity and so on-from having implications for permissibility. So if you think that legitimacy is a right, and if the benign fanatics are thought to exercise a right to rule, this will isolate their decisions from many forms of criticism.

In particular, there is a strong reason to think that rights immunise us against moral criticism directed towards our intentions. Assume that our Gangster is an army commander, endowed with some bundle of rights to command his soldiers.

\footnotetext{
18 This idea is widely accepted in the literature-e.g. Rawls (1993, p. 428).

19 I am not here taking a position on the stronger claim that we have a right to do wrong. Some authors will accept this, in which case the argument in the text will become even stronger.
} 
There are a couple of ways in which the Gangster could lose his right to command: for example, if one of his superior officers revoked his right to command, or if he treated his soldiers inhumanely, or if he commanded them to commit war crimes. But it does not seem that having certain kinds of intentions is amongst these conditions. We do not generally lose rights, and the exercise of our rights does not generally become impermissible, because of inadmissible intentions we have when we exercise those rights. There is no reason to think that rights of governments are fundamentally different in this respect. So it is natural to think that governments do not generally lose legitimacy, understood as the right to rule, because of inadmissible intentions they have when they govern.

For some other authors, legitimacy is the permission to rule-in particular, the permission to coerce (e.g. Buchanan 2002). On this understanding, the case for political anti-intentionalism follows analogous arguments in the moral case more closely. We can transpose, for example, Scanlon's distinction between the 'meaning' of an action and its legitimacy. We can say that the fanatics' intentions make their action blameworthy. But legitimacy is not identical to blameworthiness; it makes sense to say that a political decision was both legitimate and blameworthy, or legitimate but deserving of other negative moral criticism.

\section{Mattering Fundamentally}

We can now turn to another strategy we have already encountered, which emphasises that intentions need to matter fundamentally. There are certainly cases where intentions matter derivatively to political legitimacy. For example, a group of people might freely enter a social contract which specifies that their government can only act for public reasons. For a government subject to this social contract, giving the right reasons and having the right intentions is necessary for the legitimacy of its decisions.

There are also cases where intentions change the consequences. An understandable fear regarding the benign fanatics is that they will turn into authoritarian theocrats, and that non-believers will sooner or later be treated unjustly. If the benign fanatics' rule did have such a tendency, then this would indeed undermine their claim to legitimacy. But the explanatory feature in this case is non-intentional: it is the threat of injustice which puts a question mark on their legitimacy, not their intentions.

Our intuitions are severely confounded in this area because we are used to a pattern where governments with bad intentions also do bad deeds. Let us try to modify the example to exclude such confounding factors. Assume that we have strong, reliable separation of powers, and our religious fanatics merely hold a majority in the legislature, while the executive is held by secular liberals. The executive branch faithfully adopts the system of social redistribution legislated by the benign fanatics. Let us stipulate that under these conditions there is no danger of the system turning awry over time, as the liberals in the executive would reliably oppose any theocratic tendencies. As before, the intentions behind the system of 
social redistribution are illiberal. But if we properly disentangle the different orders of fundamentality, it becomes harder to think that intentions genuinely matter.

We can use the current strategy to answer another worry you might have about the benign fanatics. The Gangster has bad intentions, but he does not publicly state them. Imagine that Publicus is just like the Gangster. But in addition to ordering his coffee, he tells Smith how he thinks of him: that is, as someone not worthy of his respect, to whom he would do whatever he saw fit if it provided him with mild enjoyment. We might argue that while the Gangster acts permissibly, Publicus does not. You might think that governments are much more like Publicus, and less like the Gangster.

However, when Publicus makes his announcement, Smith can reasonably interpret this as a threat. Publicus no longer simply orders a coffee, he orders a coffee in a threatening way. It is wrong to threaten Smith in such ways, but this is so no matter what your intentions. Instead, assume that Publicus publicly announces what he thinks of Smith. He then programs a robot to buy him coffee. The program reads 'queue, order, wait, pay'. Smith knows this program, and that the robot will execute it faithfully. It seems that it was impermissible for Publicus to announce his intentions, but it is hard to think it impermissible for him to send his robot to buy coffee, as the robot does not threaten Smith.

Similar remarks apply to the benign fanatics. If they publicly announce the inferiority of non-believers as part of the justification for their policies, then some citizens will reasonably assume that the benign fanatics do not recognise their equal moral status. It would be wrong for any government to so demean and degrade its citizens. But this might well leave the legitimacy of the welfare reform itself untouched. We can again focus on the case where the fanatics only hold the legislature, and where the executive administers the system of social redistribution neutrally and fairly. The executive is similar in this respect to the Gangster's robot. Given this modified example, I think that we should reject the proposed counterexample. This system of social redistribution is legitimate even if the religious intentions behind it are publicly articulated.

One objection I have heard made at this point is that political anti-intentionalism becomes uninteresting if it only claims that intentions do not matter fundamentally. ${ }^{20}$ If anti-intentionalism accepts that intentions matter after all, so I would reconstruct this objection, as it looks like an excessively weak claim. All we care about is whether intentions matter period, and my anti-intentionalist concedes this crucial point.

In response, we can sketch some potential implications of anti-intentionalism. First, consider the legitimacy of a law that restricts the franchise, for example on the basis of a competence test. ${ }^{21}$ In most countries, such tests would disproportionately exclude minorities and the poor from the vote. What is more, we know that such laws are often proposed with precisely this intended effect, not out of any concern for the political quality of democracy. An intentionalist might think that such bad

\footnotetext{
${ }^{20}$ Maxime Lepoutre and Tom Sinclair have made this point to me. An anonymous reviewer has also pressed me on the practical implications of anti-intentionalism.

21 E.g. along the lines of Brennan (2016).
} 
motives are enough, by themselves, to undermine the legitimacy of this law, or that they at least severely put its legitimacy in question. However, if anti-intentionalism was true, the latter ground would provide us with no reason to question the legitimacy of the law.

So if this matter came before a court, the question of whether the law-makers had evil or benign reasons to restrict the franchise would be neither here nor there. ${ }^{22}$ At least, this kind of information would not be directly relevant. There would be a burden of proof to show that the intentions of the law-makers would have made a difference to the practical implementation of the law or to its expected outcomes; but without any such evidence, we would set the matter of intentions aside. The point here is not that anti-intentionalism will favour disenfrachisement instead. A law restricting the franchise might be objectionable on many other, non-intentional grounds. The difference between an intentionalist and anti-intentionalist is rather in what counts as a relevant factor in evaluating the legitimacy of a law.

Similarly, good intentions would also not make a difference if anti-intentionalism was true. Assume that a government intended to improve social justice through increasing the minimum wage; but in this instance, the measure backfires, and it worsens the economic position of those the law was meant to help. An intentionalist might claim that the good intention behind the policy goes some way to show that it was legitimate. For the anti-intentionalist, this is an irrelevant concern as far as legitimacy is concerned, though knowing about the government's intentions might lead us to excuse the government, or hold its officers blameless. Again, there are other reasons why we might think this law legitimate on which both intentionalists and anti-intentionalists agree-for example, because it was decided by the rightly elected government. Still, something has changed in how we approach the problem: that our government meant well is now irrelevant.

In short, anti-intentionalism does make a difference, at the very least on how we approach various practical problems. In some cases, it will also directly affect allthings-considered judgements about legitimacy-e.g. if the intentions behind a law restricting the franchise are the deciding factor in thinking it illegitimate.

\section{Outward-Looking Political Morality}

Lastly, I want to consider the political analogue of Scanlon's claim that permissibility is outward-looking. Scanlon claims that permissibility has its functional place in the deliberation of agents; and because intentions do not matter when agents deliberate, they do not matter to permissibility. There is no precisely analogous argument in the political realm. One of the functions of judgements about legitimacy-perhaps even the primary function-is to provide citizens and observers with a means to assess laws, rulers and policies, especially in the face of disagreement (see Applbaum 2004, p. 84).

\footnotetext{
22 Insofar as this was a philosophical court merely deciding legitimacy. Real-life legal systems might make reference to intentional criteria, of course.
} 
Still, it is the form of Scanlon's argument which is promising: to start from the role which permissibility plays in our moral thinking. Similarly, we can ask what role the value of legitimacy plays. The answer depends a bit on the precise way in which we understand the concept, but I think we can make some high-level observations which are independent from particulars. To call something legitimate always means to bestow some privileged moral status on it. If you think legitimacy entails authority, then you are required to obey and defer to a legitimate decision. If you believe that legitimacy is some property weaker than this, a legitimate decision is still one which is binding in some sense: a legitimate policy usually ought not to be actively undermined, and demands our respect and perhaps support and compliance.

This, by itself, is not that different from the concept of permissibility. What is different in the political case is that legitimacy tends to be concerned with collective problems which we need to solve together. We have to decide which political decisions we regard as binding, demanding respect and deference, and which we do not regard in such ways. ${ }^{23}$ What is crucial in such cases is that we coordinate on the same, or at least roughly similar, judgements about legitimacy. ${ }^{24}$ Political aims are normally collective aims which we can only achieve together. We have duties of justice, for example: a duty to secure the basics of public order, to allow everyone the opportunity to lead decent and self-respecting lives and so on. These duties cannot be discharged easily by ourselves, if at all. So establishing justice usually requires a highly organised state with a monopoly of power over a given territory. One plausible function of the benign fanatics' welfare reform, for example, is to change the way in which we discharge duties of redistributive justice. Thus, calling the fanatics' reform 'legitimate' entails, in this important sense, that the system they wish to implement should work as a binding plan for all of us: the plan how we aim to pursue justice for now.

Observations about the necessity to coordinate can be made across a variety of political theories. Egalitarian theories will demand that we engage in elaborate schemes of resource redistribution, which will be nearly impossible to achieve without coordination. If you think, on the other hand, that we have no or few positive duties of justice, it is still plausible to think that our natural duties of justice are gravely indeterminate. On a Lockean theory of rights and property acquisition, for example, we need to agree on an interpretation of the Lockean proviso, and under what conditions we count consent to political authority as valid. So even for such a view it is important that we have some shared, coordinated understanding of the conditions of legitimacy.

So coordination is crucial to legitimacy across a variety of views. I would wager that it is the crucial function of legitimacy judgements to coordinate solutions to difficult collective political problems. The same is not generally true when it comes to permissibility. We need not usually agree on what we think to be permissible.

\footnotetext{
${ }^{23}$ I set aside the question of who the relevant 'we' is-for our purposes, we can think of the relevant group of people as the citizens of a particular state.

24 The necessity to coordinate in politics has been stressed by various authors-e.g. Finnis (1989), Waldron (1999, pp. 101-105).
} 
You might think that eating meat is permissible, while I think that it is impermissible. It is important to get this matter right. But for us to discharge our duties relating to animals, no coordination of our behaviour is necessary. Similarly, the Gangster has various duties against Smith, but he need not first agree with Smith on any particular scheme which specifies how this is to be done-he simply should not treat Smith in certain ways.

If legitimacy is an essentially coordinative value, then we will expect it to have some structural features. One of these features we have already encountered briefly, a strong separation between the substantive merits of a decision and its legitimacy. Politics is characterised by deep, lasting and reasonable disagreement about what should be done. If we could make judgements of legitimacy only on the basis of widely divergent beliefs about which policies are good, just or efficient, then legitimacy could not play its coordinating function. Legitimacy would just reproduce the disagreements it was meant to overcome. ${ }^{25}$ So showing that a decision is legitimate will not primarily depend on arguing that it has various goodmaking features. ${ }^{26}$

On the flipside, the coordinating function of legitimacy explains the appeal of proceduralist approaches to legitimacy. If legitimacy is primarily a question of which people have been elected into which offices, and whether they have at appropriate times made certain choices in certain procedurally prescribed ways, then we can bracket out many of our substantive disagreements. Indeed, our disagreements are now channelled into this procedural apparatus: claims about how we collectively ought to discharge important duties are resolved through elections and representative political bodies.

What does this entail for anti-intentionalism? I believe that the coordinative function of legitimacy supports to construe legitimacy as an outward-looking value - that is, one that focusses on clearly identifiable, external features of policies and political outcomes, and sets aside the intentions, beliefs and desires of those making these policies. We should focus on what rulers $d o$; but we should bracket out, as far as we can, substantive judgements about the intentions and motives which people have. The idea is a generalised version of the argument I gave previously. There I argued that rights have the function to immunise us from certain kinds of criticism, and so are outward-looking. For this reason we should expect legitimacyas-right to be outward-looking as well. But even if we do not conceive of legitimacy as a right to rule, we can identify an important function of legitimacy, its coordinative function, and this further supports to see it as outward-looking.

\footnotetext{
25 This argument is closely related to Waldron's argument for normative positivism - the idea that we should see law as morally neutral to avoid substantive debates seeping into questions of legal validity (Waldron 1996).

26 There will also be disagreements about legitimacy itself. Just as much as we disagree about how our society ought to be organised, we disagree about the correct way of resolving our disagreement regarding that issue. But note that we need not agree on the best way of resolving our first-order disagreements, we only need to agree on $a$ way to do so. It is also not necessary for the pursuit of justice that everyone coordinate their behaviour all the time; legitimacy can still play its coordinating function in the face of disagreements regarding particular issues. It is more difficult to say what should be done if we cannot find agreement even in this very minimal sense, but I cannot answer this question here. I thank an anonymous reviewer for pressing me on the issue.
} 
We can also return to sceptical arguments regarding the metaphysical status of intentions. While I dismissed extreme scepticism, a more moderate scepticism claims that identifying the intentions of governments is difficult and unreliable (Waldron 1993, pp. 150-151; Sher 1997, pp. 20-22). Political decisions depend on the minds of a wide variety of people, whose intentions are various and often contradictory. Identifying the driving aim behind a given policy is difficult, and often relies on guesswork. Usually, we simply tend to read back from the content or consequences of a decision to the likely intentions behind it, but this is an unreliable shortcut. To clarify, I do not question that there are collective intentions, or even that in some cases we can identify them; I rely on the much weaker claim that they are hard to discern.

There are also practical disadvantages entailed by an intentionalist approach to legitimacy. Intentionalist principles make it too easy for governments to evade responsibility (Enoch 2005, pp. 56-57; Enoch 2007, pp. 90-91), and to depict their own case favourably. It is easy for a government to claim that it had good intentions, and hard to prove otherwise (Ristroph 2008). So on these grounds, we have practical reasons to avoid an intentionalist standard of legitimacy. But more importantly, the unreliability of knowing governmental intentions enhances the case for not using such forms of information as the grounds on which we make judgements of legitimacy. Governmental intentions are not the right type of defeaters for legitimacy, if our aim is to coordinate our political behaviour.

Let me note one limitation of this argument: there might be some governmental intentions which are so universally clear, and also so clearly condemnable, that they act as defeaters against a legitimate policy. For example, if a policy was made to deliberately keep a minority group destitute or powerless, we may judge it to be illegitimate on that basis alone. After all, a policy being egregiously unjust-and being widely agreed to be so-works as a defeater as well, even if we generally separate the legitimacy and the justice of a policy. The argument from coordination cannot fully exclude such cases; it cannot ground an absolute restriction on what kinds of information we work on. At any rate, while admitting such extreme cases would diminish the philosophical purity of anti-intentionalism, it does not take away from the practical import of the position. We could still rule out, for example, justificatory neutrality as a general constraint on legitimacy (see next section).

The different arguments I have tackled in this section are generic argument strategies available to the political anti-intentionalist; they do not amount to a conclusive case in favour of the position. Lots of the details in each strategy would need to be filled in by a fully worked-out theory of legitimacy-for example, which moral dimensions we aim to distinguish, and how we draw connections between them. The advantage of the strategies I have described is that they are accessible across a wide range of specific theories of legitimacy; they provide a toolbox for defending political anti-intentionalism inside the specific view of legitimacy you favour, but much more work needs to be done. 


\section{Justificatory Neutrality and Political Liberalism}

I have previously sketched some practical implications of the distinction between intentionalism and anti-intentionalism. Let me now turn to some philosophical implications the distinction has by turning to two debates in political philosophy, one about neutrality, and another about public justification. Advocates of these views, I will argue, rarely face up to the issue of intentionalism and antiintentionalism directly, despite intentionalist-sounding language.

It is common in debates about neutrality to distinguish neutrality of effect from neutrality of justification. The former demands that the state's actions have a neutral effect on competing conceptions of the good; the latter demands that the state should not act on reasons that are controversial. It is with regard to the latter that we should expect explicit statements of political intentionalism, as the 'acting on reasons' language might suggest. Some authors, in fact, phrase neutrality of justification explicitly in terms of intentions. Waldron calls it 'neutrality in relation to the motives and reasons' that the legislators use to justify laws (Waldron 1993, p. 150). Wall writes that neutrality prohibits the state from 'intend[ing] to favor or promote' one conception of the good over others (Wall 2010, p. 239). Patten classifies neutrality of justification as a variety of 'neutrality of intention' (Patten 2011, p. 255). ${ }^{27}$ Raz's 'exclusion of ideals'-roughly his version of neutrality of justification-also seems to be intentionalist in that it 'forbids [governments] to act for certain reasons' (Raz 1986, p. 135).

Other authors, however, explicitly reject an intentionalist reading. Arneson phrases neutrality of justification as requiring that 'any policies pursued by the state should be justified independently of any appeal to the supposed superiority of any way of life or conception of the good over others' (Arneson 2003, p. 193). But he distinguishes this from neutrality of aim, which requires that the state does not aim to promote controversial conceptions of the good. Other authors join Arneson in distinguishing neutrality of justification and aim (Gaus 2009, p. 81), or in explicitly rejecting an intentionalist reading of neutrality of justification (Sher 1997, p. 23-24).

The point is that there could be a government which has non-neutral aims, but which either: (1) has publicly offered a neutral justification, even if this is not the justification it actually acts on; or (2) there is a neutral justification for its policy, though this is not a justification the government offers or acts on (see Wall 2001, p. 391; Arneson 2003, p. 194). There is a neutral justification, for example, for the welfare reform of the benign fanatics, and we can imagine that in the run-up to their decision they offer public reasons. So our benign fanatics would fulfil both (1) and (2). The crucial question for the defender of neutrality of justification is whether these two conditions are enough for the decision to count as neutral or not.

The point is that neutrality might be a constraint on the procedure we use in making political decisions-i.e. what kind of justifications governments publicly can offer when they engage citizens. Second, it might be a constraint on the content of the decisions being made-i.e. whether the decision is one that could be justified

${ }^{27}$ Note that both Wall and Patten reject neutrality of justification. 
with reference to some class of reasons. And lastly, it might be a constraint on the intentions governments have while making them-i.e. the plans and aims governments actually have in pursuing some policy. These are analytically independent requirements.

Most theorists never clearly face up to this distinction. ${ }^{28}$ They simply phrase the principle of neutrality of justification in terms which are ambiguous between an intentionalist and an anti-intentionalist reading. A similar issue reappears in another, closely related issue, the correct formulation of political (or 'justificatory') liberalism. On such views, it is a necessary condition for legitimacy that a decision - or at least the 'constitutional essentials' - can be justified to everyone. The same ambiguities reappear. The demand for justification can be read as a constraint on the content of a decision. Read this way, we demand that policies ought to be such that there is a justification for them that everyone could accept, no matter whether government actually acts on the basis of that justification. Alternatively, we could read it as a constraint on intentions: decisions ought to be made by rulers only on the basis of reasons they think everyone could accept, and they must intend to act in ways that are publicly justifiable.

Most papers on the issue are not clear on whether political liberalism makes an intentionalist demand, or whether we can cash it out in non-intentionalist terms. The ambiguity can be seen, for example, in Rawls's 'liberal principle of legitimacy' which states that

our exercise of political power is fully proper only when it is exercised in accordance with a constitution the essentials of which all citizens as free and equal may reasonably be expected to endorse in the light of principles and ideals acceptable to their common human reason. (Rawls 1993, p. 137)

The crucial question to ask is from whose perspective the constitutional essentials need to be 'expected' to be acceptable to everyone. Do those who exercise power need to expect, and aim for, the acceptance of everyone? That would give us an intentionalist reading. Or is it enough for legitimacy if it turns out that the constitutional essentials can be endorsed by everyone, independent from whether government, or the writers of our constitution, aimed for this? That would provide merely a constraint on content. The exegetical question in Rawls is difficult. I suspect that the textual evidence can support either reading. The distinctions made in this paper suggest ways in which the debate can be made more explicit.

The difference between an intentionalist and an anti-intentionalist reading of political liberalism, and of neutrality about justification, might at first sight look like a merely technical difference. But I do not think this is the case. Neutrality in intention and neutrality in content, for example, are fundamentally different demands. One puts prime importance on the mental states of the agent, another entirely ignores it. It would be curious if these two different types of position can be supported by the same arguments and examples, or would have the same political

\footnotetext{
${ }^{28}$ Patten (2011, pp. 254-255) is the main exception. However, Patten classifies both neutrality of justification and neutrality of aim as species of neutrality of intention. This strikes me as inadequate given that authors who introduce the aim/justification distinction use it to move neutrality of justification away from neutrality of intention.
} 
implications. Let me only briefly sketch how different foundations for political liberalism will affect whether we should choose an intentionalist or antiintentionalist reading.

Assume, for example, that you defend political liberalism on the basis of some demand of equal respect: political decisions which are not acceptable to every reasonable person, you think, show a lack of respect for the rational autonomy of those who disagree (e.g. Larmore 1999). Let us interpret this demand for justification as a right that individuals possess. What plausibly matters on this reading is that we ought not to treat others in certain ways, in particular, not coerce them in ways they could not accept. Phrased this way, it is likely you will end up with an anti-intentionalist reading: it is (primarily?) the treatment you receive that matters. Insofar as governmental intentions do not affect how you are treated, it is not immediately clear how we should think them relevant.

Alternatively, you might argue for political liberalism on the basis of a demand for political community (e.g. Lister 2013). You might think it important that we only act in ways justifiable to others so that we form a kind of community in which we can rely on others, and know that others will see and respect us in certain ways. This approach is much more likely to incline you towards an intentionalist reading of political liberalism. Governments which merely act in justifiable ways but do not show the right type of concern for the community we wish to form will look morally problematic on this view.

In short, I suspect that the different ways to interpret neutrality and political liberalism also reflect deeper, diverging motivations for these positions, which some of the existing literature might obscure. In much the same way, these different readings will also have different practical implications. For example, the antiintentionalist neutralist should judge the benign fanatics' policies to be fully legitimate; the intentionalist neutralist has at least some grounds to think them problematic in terms of legitimacy. Again, these issues are usually obscured because the legitimacy, or lack of legitimacy, of many policies is severely overdetermined. Still, it might pay off to be precise.

Acknowledgements I thank audiences at Oxford and Pavia, and Jessica Laimann, Maxime Lepoutre, Andrew Lister and Tom Sinclair for comments on previous versions of this paper.

Open Access This article is distributed under the terms of the Creative Commons Attribution 4.0 International License (http://creativecommons.org/licenses/by/4.0/), which permits unrestricted use, distribution, and reproduction in any medium, provided you give appropriate credit to the original author(s) and the source, provide a link to the Creative Commons license, and indicate if changes were made.

\section{References}

Applbaum, Arthur Isak. 2004. 'Legitimacy in a Bastard Kingdom.' John F. Kennedy School of Government Center for Public Leadership Working Papers. http://dspace.mit.edu/handle/1721.1/ 55927.

Arneson, Richard. 2003. Liberal neutrality on the good: An autopsy. In Perfectionism and neutrality: Essays in liberal theory, ed. George Klosko, and Steven Wall, 191-218. Lanham, MD: Rowman \& Littlefield. 
Buchanan, Allen. 2002. Political legitimacy and democracy. Ethics 112: 689-719.

Brennan, Jason. 2016. Against democracy. Princeton, NJ: Princeton University Press.

Copp, David. 2006. On the agency of certain collective entities: An argument from 'normative autonomy'. Midwest Studies in Philosophy 30: 194-221.

Cryer, Robert, and A. P. Simester. 2005. Iraq and the use of force: Do the side-effects justify the means? Theoretical Inquiries in Law 7: 9-41.

Enoch, David. 2005. Ends, means, side-effects, and beyond: A comment on the justification of the use of force. Theoretical Inquiries in Law 7: 43-57.

Enoch, David. 2007. Intending, foreseeing, and the State. Legal Theory 13: 69-99.

Finnis, John. 1989. Law as co-ordination. Ratio Juris 2: 97-104.

Gaus, Gerald. 2009. The moral foundations of liberal neutrality. In Contemporary debates in political philosophy, ed. Thomas Christiano, and John Philip Christman. Malden, MA: Wiley-Blackwell.

Hanser, Matthew. 2005. Permissibility and practical inference. Ethics 115: 443-470.

Herman, Barbara. 2011. A mismatch of methods. In On what matters, vol. 2, ed. Derek Parfit, 83-115. Oxford: Oxford University Press.

Kamm, Frances. 2007. Intricate ethics. New York, NY: Oxford University Press.

Kolodny, Niko. 2011. Scanlon's investigation: The relevance of intent to permissibility. Analytic Philosophy 52: 100-123.

Larmore, Charles. 1999. The moral basis of political liberalism. Journal of Philosophy 96: 599-625.

Liao, Matthew. 2012. Intentions and moral permissibility: The case of acting permissibly with bad intentions. Law and Philosophy 31: 703-724.

List, Christian, and Philip Pettit. 2011. Group agency: The possibility, design, and status of corporate agents. Oxford: Oxford University Press.

Lister, Andrew. 2013. Public reason and political community. London: Bloomsbury Academic.

McMahan, Jeff. 2009. Intention, permissibility, terrorism, and war. Philosophical Perspectives 23: 345-372.

Parfit, Derek. 2011. On what matters, vol. 1. Oxford: Oxford University Press.

Patten, Alan. 2011. Liberal neutrality: A reinterpretation and defense. Journal of Political Philosophy 20: 249-272.

Rawls, John. 1993. Political liberalism. New York, NY: Columbia University Press.

Raz, Joseph. 1986. The morality of freedom. Oxford: Oxford University Press.

Ristroph, Alice. 2008. State intentions and the law of punishment. Journal of Criminal Law and Criminology 98: 1353-1406.

Rossi, Enzo, and Matt Sleat. 2014. Realism in normative political theory. Philosophy Compass 9: 689-701.

Scanlon, Thomas. 2008. Moral dimensions: Permissibility, meaning, blame. Cambridge, MA: Belknap Press of Harvard University Press.

Sher, George. 1997. Beyond neutrality: Perfectionism and politics. Cambridge, New York: Cambridge University Press.

Simmons, John. 1999. Justification and legitimacy. Ethics 109: 739-771.

Sverdlik, Steven. 1996. Motive and rightness. Ethics 106: 327-349.

Sverdlik, Steven. 2011. Motive and rightness. Oxford: Oxford University Press.

Thomson, Judith Jarvis. 1985. The trolley problem. Yale Law Journal 94: 1395-1415.

Thomson, Judith Jarvis. 1999. Physician-assisted suicide: Two moral arguments. Ethics 109: 497-518.

Timmons, Mark. 2002. Motive and rightness in Kant's ethical system. In Kant's metaphysics of morals: Interpetative essays, ed. Mark Timmons, 255-288. Oxford: Oxford University Press.

van Zyl, Liezl. 2008. Accidental rightness. Philosophia 37: 91-104.

van Zyl, Liezl. 2010. Motive and right action. Philosophia 38: 405-415.

Waldron, Jeremy. 1993. Liberal rights: Collected papers, 1981-1991. Cambridge: Cambridge University Press.

Waldron, Jeremy. 1996. Kant's legal positivism. Harvard Law Review 109: 1535-1566.

Waldron, Jeremy. 1999. Law and disagreement. Oxford: Clarendon Press.

Walen, Alec. 2006. The doctrine of illicit intentions. Philosophy \& Public Affairs 34: 39-67.

Wall, Steven. 2001. Neutrality and responsibility. Journal of Philosophy 98: 389-410.

Wall, Steven. 2010. Neutralism for perfectionists: The case of restricted state neutrality. Ethics 120: 232-256. 